\title{
Acquisition of antibodies to merozoite surface protein 3 among residents of Korogwe, north eastern Tanzania
}

\author{
Method D Segeja*, Bruno P Mmbando, Misago D Seth, John P Lusingu, Martha M Lemnge
}

\begin{abstract}
Background: A polymorphic malaria parasite antigen, merozoite surface protein 3 (MSP3), is among the blood stage malaria vaccine candidates. It is believed to induce immunity through cytophilic antibodies that disrupt the process of erythrocytes invasion by merozoites. This study aimed at assessing natural acquisition of antibodies to MSP3 in individuals living in an area with different malaria transmission intensity in preparation for malaria vaccine trials.

Methods: The study was conducted in individuals aged 0-19 years from villages located in lowland, intermediate and highland strata in Korogwe district, northeastern Tanzania. Blood samples from 492 study participants were collected between May and June 2006 for malaria diagnosis and immunological investigations. Reactivity of MSP3 to different types of antibodies (immunoglobulin $M, G$ and IgG subclass 1 and 3) were analysed by Enzyme Linked ImmunoSorbent Assay (ELISA).

Results: Malaria parasite prevalence was higher in the lowland (50\%) compared to the intermediate (23.1\%) and highland (9.8\%) strata. Immunogloblin G subclasses 1 and 3 (IgG1 \& IgG3), total IgG and IgM were found to increase with increasing age. IgG3 levels were significantly higher than $\lg G 1(p<0.001)$. Furthermore, Plasmodium falciparum infection was associated with higher lgG3 levels $(p=0.008)$. Adjusting by strata and age in individuals who had positive blood smears, both IgG and IgM were associated with parasite density, whereby lgG levels decreased by $0.227(95 \% \mathrm{Cl}: 0.064-0.391 ; \mathrm{p}=0.007)$ while IgM levels decreased by 0.165 ( $95 \% \mathrm{Cl}: 0.044-0.286$; $p=0.008)$.
\end{abstract}

Conclusion: Individuals with higher levels of lgG3 might be partially protected from malaria infection. Higher levels of total IgG and IgM in highlands might be due to low exposure to malaria infection, recent infection or presence of cross-reactive antigens. Further studies of longitudinal nature are recommended. Data obtained from this study were used in selection of one village (Kwashemshi) for conducting MSP3 phase 1b malaria vaccine trial in Korogwe.

\section{Background}

Malaria is one of the most serious public health problems in the world, affecting tropical developing countries and killing young children mainly [1]. Relationship between malaria morbidity and antibody levels to malaria antigens has been analyzed in several prospective longitudinal studies performed in different parts of Africa and Asia [2,3]. Adults develop potent but none

\footnotetext{
* Correspondence: segeja@hotmail.com
National Institute for Medical Research, Tanga Medical Research Centre, PO

* Correspondence: segeja@hotmail.com Box 5004, Tanga, Tanzania
}

(c) 2010 Segeja et al; licensee BioMed Central Ltd. This is an Open Access article distributed under the terms of the Creative Commons Attribution License (http://creativecommons.org/licenses/by/2.0), which permits unrestricted use, distribution, and reproduction in any medium, provided the original work is properly cited. chronically harbor low grade parasitaemia and only occasionally suffer from mild clinical state known as premunition $[4,5]$.

Currently, a number of malaria vaccines candidates are at different stages of clinical development. Promising results have been obtained with some of the vaccine candidate [6-8]. Among the blood stage candidate vaccines, merozoite surface protein 3 (MSP3) of Plasmodium falciparum offers good prospects for a potent vaccine whereby epidemiological and laboratory data suggest that, immune responses targeting this antigen is 
associated with protection [9]. It is believed that immunity induced by MSP3 is through cytophilic antibodies that disrupt the process of invasion of erythrocytes by merozoites [10]. Antibodies can exert their inhibitory function by preventing merozoite invasion into erythrocytes [11], by activating monocytes via cytophilic effective IgG1 and IgG3 isotypes [12] or by inhibiting cytoadherence of infected erythrocytes. Previous studies have demonstrated that immunoglobulin G (IgG) from individuals who are immune to malaria could passively transfer immunity to naïve infected recipients [11]. Immunoglobulin $\mathrm{G}$ cooperates with monocytes in a mechanism of antibody-dependent cellular inhibition of parasite growth (ADCI) in vitro [13]. Individuals protected against malaria produce mostly cytophilic antibodies (IgG1 or IgG3), whereas non-protected subjects produce mostly IgG2 and IgM $[2,14]$. Clinical trials of MSP3 vaccine in healthy, semi-immune adult males in Burkina Faso and children aged 12 to 24 months old in Tanzania showed it was safe and immunogenic $[15,16]$.

The aim of this study was to employ a standardized ELISA assay to assess natural acquisition of antibodies to MSP3 in individuals living in an area with different malaria transmission intensity in preparation for malaria vaccine trials.

\section{Methods}

\section{Study area and population}

This study was conducted in Korogwe district, northeastern Tanzania. The district is about 100 kilometers inland from Tanga. The population of Korogwe district in year 2002 (National census survey) was estimated to be 261,004 , with a growth rate of $1.4 \%$ per annum. The area is topographically stratified into three strata namely; lowland, intermediate and highland. The strata are characterized by marked differences in malaria transmission profiles. The altitude of Korogwe district ranges from 300 - 1,200 meters above sea level (mASL). In these areas, malaria transmission decreases with increasing altitude $[17,18]$ and is highest during and following the long rainy season, which usually extends from March through July. Low transmission is experienced during short rains of October - December. However, a recent study has shown non-significant differences in malaria prevalence between the two seasons [19].

In Korogwe district, the estimated average entomological inoculation rate (EIR) ranges in the past from 30100 infective bites per person per year [17]. In lowland villages of Korogwe, malaria is perennial with peak seasons during and just after the rain [20]. P. falciparum is the predominant malaria species accounting for a little over $90 \%$ of all infections, the rest being P. malariae and $P$. ovale [21]. In Korogwe District Hospital, malaria is the leading cause of admission and deaths among underfive children [22].

Study villages were grouped into three strata namely; lowland, intermediate and highland based on the altitude and level of transmission. Mng'aza village was categorized as lowland stratum, Kwashemshi village as intermediate while Magundi, Kwamhanya and Vugiri villages were grouped into highland stratum. The study involved individuals aged 0-19 years. The details of the study villages are as explained elsewhere [19].

\section{Study design}

This study was part of a longitudinal project being conducted in Korogwe. Samples used in this study were obtained from a cross sectional malaria survey conducted in May and June 2006 [19]. Plasma samples from 492 individuals (66 lowlands, 121 intermediate and 305 highlands) were analyzed by Enzyme Linked ImmunoSorbent Assays (ELISAs). A sample size of 89 samples from each stratum was estimated assuming a proportional mean difference of antibody levels to MSP3 between any two strata to be $30 \%$ and coefficient of variation of $90 \%$; this variation has been also shown to vary with transmission elsewhere [23]. Thus, a minimum sample size of 270 was required from the three strata. For the purpose of assessing the effect of age on acquisition of antibodies, individuals were categorized into four age-groups 0-2, 3-4, 5-9 and 10-19 years. Over sampling was done in the highland area, because the villages were initially earmarked for MSP3 phase 1b vaccine trial [24].

\section{Ethical consideration}

Ethical clearance was granted by the Medical Research Co-ordinating Committee of the National Institute for Medical Research and the Ministry of Health and Social Welfare, Tanzania. Prior to commencement of the study, sensitization meetings were held in each village to explain the objectives and methodology of the study as well as seeking for community consent. Informed consent was obtained in writing from all individual participants or parents/guardians in case of children during the survey as described elsewhere [19].

\section{Blood sample collection}

Clinical examination was done in all 492 individuals at a central point in each village. Venous blood (about $3 \mathrm{ml}$ ) from each individual was drawn into vacutainer containing EDTA anticoagulant. Out of the $3 \mathrm{ml}$ of blood collected, $8 \mu \mathrm{L}$ was used for preparation of thick and thin blood smears for malaria parasite diagnosis, species identification and quantification. Also, $10 \mu \mathrm{L}$ of blood of each individual was used for estimation of haemoglobin using Haemocue ${ }^{\oplus}$ machine. The remaining blood was centrifuged at 2,000 revolutions per minute (rpm) to 
obtain plasma, packed red blood cells (RBCs) and buffy coat. Plasma was stored at $-80^{\circ} \mathrm{C}$ and later analyzed for immunological assays.

\section{Determination of antibody responses to MSP3 by ELISA}

Plasma samples were used to determine levels of IgM, total IgG and IgG subclasses (IgG1 \& IgG3) responses to MSP3 malaria vaccine candidate by Enzyme Linked ImmunoSorbent Assay (ELISA) technique as described elsewhere http://www.amanet-trust.org. Briefly, wells of the microtiter plates (Nunc, Roskilde, Denmark) were coated with $100 \mu \mathrm{L}$ at $0.5 \mu \mathrm{g} / \mathrm{ml}$ of a recombinant protein covering the nonpolymorphic carboxy-terminal region of the MSP3 protein (aa 212 - 380) [10]. The antigen was supplied as a stock solution of $2.4 \mathrm{mg} / \mathrm{ml}$ and had to be diluted so as to obtain a working concentration of $0.5 \mu \mathrm{g} / \mathrm{ml}$. The plates were incubated overnight at $4^{\circ} \mathrm{C}$, washed four times and blocked using (150 $\mu \mathrm{L}$ per well) $3 \%$ skimmed milk in phosphate buffered saline (PBS) -Tween 20 (Blocking Buffer) for 1 hour. Plasma samples $(100 \mu \mathrm{L} /$ well) at dilutions of 1:200 (for total IgG and IgM) and 1:50 (for IgG subclasses) were added in duplicate wells and incubated at room temperature $\left(20-24^{\circ} \mathrm{C}\right)$ for 2 hours. Plates for IgG1 and IgG3 were then incubated for 1 hour with monoclonal mouse anti-human IgG1 and IgG3 (Skybio, Wyboston Bedfordshire, UK) as secondary antibodies at dilutions of 1:2000, and 1:5000 respectively. The plates were washed four times between aforementioned steps. Colour development was achieved either with horseradish peroxidase-conjugated goat anti-human total IgG and IgM (Caltag, Burlingame, CA) respectively, or horseradish peroxidase-conjugated goat anti-mouse IgG (Caltag, Burlingame, CA) for IgG subclasses followed by $\mathrm{H}_{2} \mathrm{O}_{2}$ with tetramethylbenzidine (TMB) substrate (Kem-EnTec diagnostics, Kuldyssen, DK). Absorbance was read at $450 \mathrm{~nm}$ with reference at $650 \mathrm{~nm}$. For each antibody isotype, a calibration (standard) curve was obtained from two-fold serially diluted purified myeloma proteins coated directly to duplicate wells of the first two columns of each plate. First well concentrations in ng/ ml were: 100 (IgG \& IgG3), 500 (IgG1) and 250 (IgM). Four pooled plasma from clinically immune adult Liberians and two Danish donors never exposed to malaria were used as positive and negative controls respectively. Antibody units were calculated using the Afro Immuno Assay (AIA) Network protocol of 2005 volume 1.01 excel based curve fitting program as described elsewhere [25].

\section{Data analysis}

All data were entered and verified in Microsoft Access while statistical analysis was done using $\mathrm{R}$ version 2.8.0 and STATA software version 8 (stata Corp., College station, TX). All antibody levels were transformed to normality using the log transformation. Malaria parasite densities were converted from parasites per 200 white blood cells (WBCs) to parasite per microliter $(\mu \mathrm{L})$ by multiplying by 40 . A multiple regression analysis was used to assess variables associated with antibody levels. A p-value $<0.05$ was considered significant.

\section{Results}

\section{Malaria infection}

Table 1 gives the baseline characteristics of individuals living in the three strata during May/June 2006 crosssectional survey. Out of the 492 selected individuals, 305 (62\%) were from highland stratum, 121 (24.6\%) were from intermediate stratum and 66 (13.4\%) were from lowland stratum. Overall, malaria parasites prevalence was 20.5\% (101 out of 492). Distribution of P. falciparum parasite prevalence in the three strata were $50.0 \%$ (95\% CI: $37.4-62.6)$ in the lowland stratum, 23.1\% (95\%CI: 16.0 - 31.7) in the intermediate stratum and 9.8\% (95\%CI: 6.7 - 13.7) in the highland stratum. Intermediate stratum had low malaria parasite prevalence but its geometric mean parasite density (GMD) among the positive cases was the highest among the three strata (424 rings/ $\mu \mathrm{L} ; 95 \% \mathrm{CI}$ : 187 - 964). Bednet use was highest $(91.4 \%)$ in the intermediate stratum.

Table 1 Baseline characteristics of individuals sampled from lowland, intermediate and highland strata in Korogwe, Tanzania

\begin{tabular}{|c|c|c|c|c|c|}
\hline Strata -Village & $\begin{array}{l}\text { Altitude (mASL) } \\
\text { (n = sample size) }\end{array}$ & $\begin{array}{l}\text { P. falciparum prevalence } \% \\
(95 \% \mathrm{Cl})\end{array}$ & $\begin{array}{l}\text { P. falciparum GMD } \\
(95 \% \mathrm{Cl})^{\delta}\end{array}$ & $\begin{array}{l}\text { Splenomegaly prevalence \% } \\
(95 \% \mathrm{CI})\end{array}$ & $\begin{array}{l}\text { Bednet use } \\
\%\end{array}$ \\
\hline Lowland-Mng'aza & $334(n=66)$ & $50.0(37.4,62.6)$ & $316(173,578)$ & $30.8(20.0,43.4)$ & 24.6 \\
\hline Intermediate-Kwashemshi & $409(n=121)$ & $23.1(16.0,31.7)$ & $424(187,964)$ & $5.8(2.4,11.6)$ & 91.4 \\
\hline Highland-Magundi & $638(n=128)$ & $14.1(8.6,21.3)$ & $237(133,421)$ & $10.9(6.1,17.7)$ & 17.19 \\
\hline -Kwamhanya & $761(n=86)$ & $5.8(1.9,13.0)$ & $314(63,1562)$ & $4.7((1.3,11.2)$ & 58.14 \\
\hline -Vugiri & $941(n=91)$ & $7.7(3.1,15.2)$ & $2020(271,15042)$ & $1.1(0.3,5.9)$ & 46.15 \\
\hline Average(Highland) & $780(n=305)$ & $9.8(6.7,13.7)$ & $409(218,765)$ & $5.0(2.8,8.1)$ & 37.4 \\
\hline
\end{tabular}

$\mathrm{n}=$ number sampled, $\mathrm{mASL}=$ meters above sea level, GMD $=$ Geometric mean density, $\%=$ percentage, $95 \% \mathrm{Cl}=95 \%$ confidence interval, ${ }^{\delta}$ Based on individuals who had positive slides only 
Spleen rate was higher in the lowland (30.8\%) compared to the other two strata.

\section{Immunoglobulin G1 (IgG1 subclass)}

Individuals living in lowlands had higher IgG1 antibody levels compared to negative controls while individuals aged 10-19 years had higher mean levels than positive control (Figure 1). Results show that levels of IgG1 adjusted for other covariates were significantly lower in both intermediate by 1.653 (95\%CI: $1.218-2.088$; p < 0.001 ) and in highland strata by 1.229 (95\%CI: 0.853 1.605 ; $\mathrm{p}<0.001$ ), when compared to the lowland stratum. Increase in mean haemoglobin concentration $(\mathrm{Hb})$ by $1 \mathrm{~g} / \mathrm{dL}$ was associated with decrease in IgG1 levels by
0.100 (95\%CI: $0.008-0.192 ; \mathrm{p}=0.035)$. No statistically significant association was found between IgG1 levels and presence of $P$. falciparum parasites (Table 2).

\section{Immunoglobulin G3 (IgG3 subclass)}

Individuals living in lowlands had higher IgG3 antibody levels compared to negative controls while individuals aged 10-19 years had higher mean levels than positive controls (Figure 1). A pattern similar to that of IgG1 antibody levels was seen for IgG3, with intermediate and highland strata having significantly lower mean antibody levels compared to lowland stratum (Table 2).

The increase in IgG3 levels with age was 0.190 (95\% CI: $0.159-0.221 ; \mathrm{p}<0.001)$ and was slightly higher
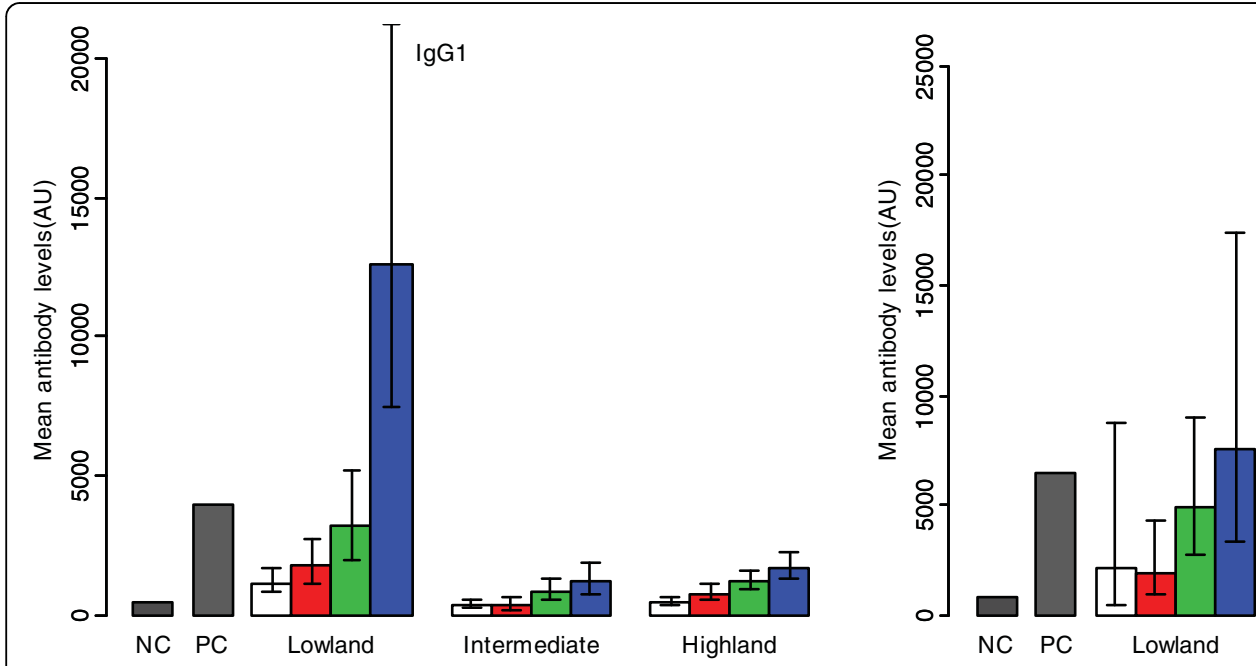

$\lg \mathrm{GO}$

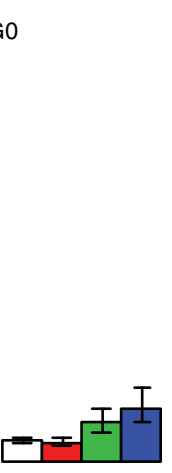

Intermediate

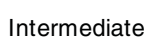

Highland

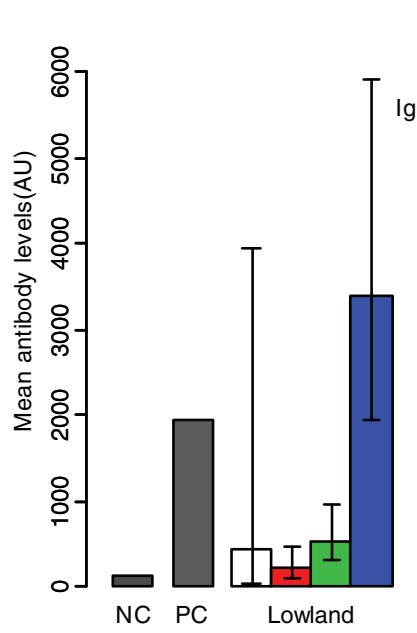

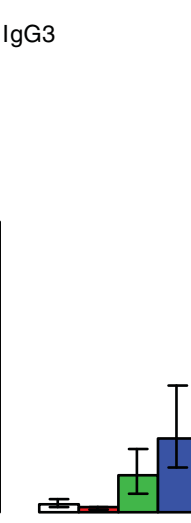

Intermediate

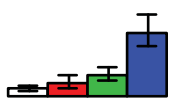

Highland

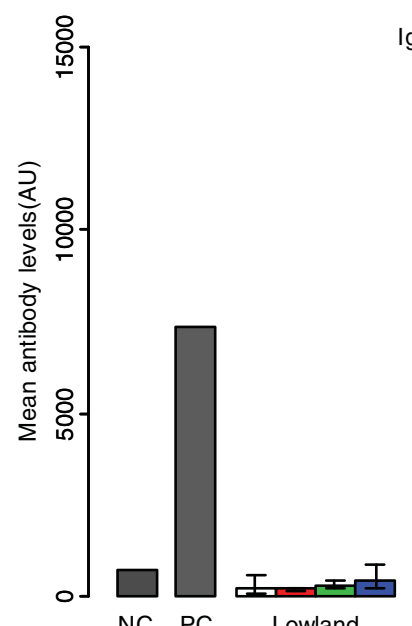

$\lg \mathrm{M}$

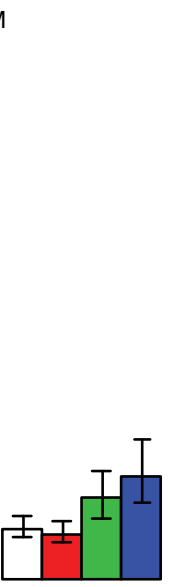

Intermediate
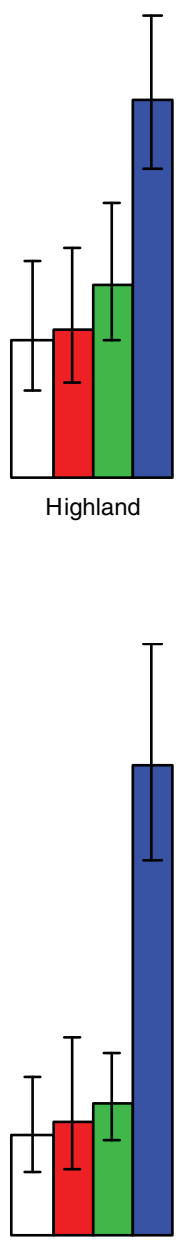

Highland

Figure 1 Distribution of geometric mean levels of $\operatorname{lgG} 1$, IgG3, total IgG and IgM (AU) to MSP3 by age-groups and strata. Children 0-2 years (open bars), 3-4 years (red bars) 5-9 years (green bars) and 10-19 years (blue bars) and line segments represent $95 \% \mathrm{Cl}$. NC = Mean of negative controls and $P C=$ mean of positive controls for respective antibodies against MSP3. 
Table 2 Linear regression estimates of parameters for variables associated with antibodies to MSP3 in Korogwe, Tanzania

\begin{tabular}{lllll}
\hline Variable & IgG1 & IgG3 & IgM & IgG0 \\
\hline Intercept & 8.363 & 5.324 & 4.672 & 6.906 \\
& $(7.352,9.374 ; p<0.001)$ & $(4.154,6.494 ; p<0.001)$ & $(3.651,5.693 ; p<0.001)$ & $(5.871,7.941 ; p<0.001)$ \\
Intermediate stratum & -1.653 & -0.917 & 2.141 & -1.168 \\
& $(-2.088,-1.218 ; p<.001)$ & $(-1.419,-0.415 ; p<0.001)$ & $(1.702,2.580 ; p<0.001)$ & $(-1.613-0.723 ; p<0.001)$ \\
Highland stratum & -1.229 & -0.848 & 2.997 & 0.742 \\
& $(-1.605,-0.853 ; p<0.001)$ & $(-1.283,-0.413 ; p<0.001)$ & $(2.617,3.377 ; p<0.001)$ & $(0.358,1.126 ; p<0.001)$ \\
Age (years) & 0.120 & 0.190 & 0.089 & 0.084 \\
& $(0.093,0.147 ; p<0.001)$ & $(0.159,0.221 ; p<0.001)$ & $(0.062,0.116 ; p<0.001)$ & $(0.057,0.111 ; p<0.001)$ \\
Presence of & 0.161 & 0.498 & 0.239 & 0.101 \\
P. falciparum & $(-0.155,0.477 ; p=0.319)$ & $(0.131,0.865 ; p=0.008)$ & $(-0.080,0.558 ; p=0.143)$ & $(-0.222,0.424 ; p=0.540)$ \\
Bednet use & 0.036 & 0.133 & -0.338 & 0.094 \\
& $(-0.238,0.310 ; p=0.798)$ & $(-0.185,0.451 ; p=0.411)$ & $(-0.614,-0.06 ; p=0.017)$ & $(-0.186,0.374 ; p=0.510)$ \\
Hb (g/dl) & -0.100 & -0.039 & 0.031 & 0.071 \\
& $(-0.192,-0.008 ; p=0.035)$ & $(-0.147,0.069 ; p=0.476)$ & $(-0.063,0.125 ; p=0.515)$ & $(-0.023,0.165 ; p=0.140)$ \\
\hline
\end{tabular}

IgG1 = Immunoglobulin G subclass 1, IgG3 = Immunoglobulin G subclass 3, IgG0 = Total Immunoglobulin G, IgM = Immunoglobulin M, Hb = haemoglobin, $<=$ less than, = equal

than in IgG1. Individuals who had P. falciparum infection had significantly higher log mean IgG3 levels by 0.498 (95\%CI: $0.131-0.865 ; \mathrm{p}=0.008)$.

\section{Immunoglobulin G (Total IgG)}

Individuals living in highlands had higher total IgG antibody levels compared to negative controls while individuals aged 10-19 years had higher mean levels than positive controls (Figure 1). Mean levels of total IgG were higher in highland stratum compared to intermediate and lowland strata (Figure 1). Levels of total IgG in $\log$ scale as shown in table 2, were significantly lower in the intermediate stratum by 1.168 (95\%CI: $0.723-1.613$; $\mathrm{p}<0.001$ ) and higher in the highland stratum by 0.742 (95\%CI: 0.358 - 1.126; p < 0.001) compared to the lowland stratum. Individuals who had $P$. falciparum infection had significantly high levels of total IgG by log 2.552 (95\% CI: 1.045 - 4.059, p < 0.001). Adjusting by strata and age among individuals who had positive blood smears, IgG levels were associated with parasite density, whereby, the log mean levels of IgG decrease was 0.227 (95\%CI: 0.064 - 0.391; $\mathrm{p}=0.007$ ).

\section{Immunoglobulin M (IgM)}

Individuals living in highland stratum had higher IgM antibody levels compared to negative controls while individuals aged 10-19 years had higher mean levels than positive control (Figure 1). Mean levels of IgM increased with increasing altitude, the highest levels being seen in the highland stratum (Figure 1). Log mean difference in IgM levels in the highland stratum was 2.997 (95\%CI: 2.617 3.377; $\mathrm{p}<0.001)$ and that of intermediate stratum was 2.141 (95\%CI: $1.702-2.580 ; \mathrm{p}<0.001)$ when compared to the lowland stratum (Table 2). IgM levels were also associated with bednet use, where in individuals who mentioned to use bednets, log mean levels were lower by $0.338(0.062-0.614 ; \mathrm{p}=0.017)$. Adjusting by strata and age among individuals who had positive blood smears, IgM levels were associated with parasite density, whereby, the log mean levels of IgM decrease was 0.165 (95\%CI: $0.044-0.286 ; \mathrm{p}=0.008)$. Individuals using bednets had significantly $(\mathrm{p}=0.017)$ lower IgM levels (Table 2$)$.

\section{Discussion}

A number of malaria vaccine candidates are at different stages of development and some are undergoing clinical trials. It is believed that immunity induced by MSP3 is through cytophilic antibodies that disrupt the process of invasion of erythrocytes by merozoites [10]. The aim of this study was to employ a standardized ELISA assay to assess natural acquisition of antibodies to MSP3 in individuals living in an area with different malaria transmission intensity in preparation for malaria vaccine trials.

The burden of malaria as shown by parasite prevalence and spleen rate was highest in the lowland and lowest in the highland strata as reported in other studies $[17,19,20]$. High bednet use $(91.4 \%)$ in the intermediate stratum might be the main factor for the lower than expected malaria prevalence and splenomegaly in this stratum. Lowland rural settings are normally characterized by high malaria transmission intensity as shown in our recent publication [19].

The increase in levels of total IgG, IgM, IgG1 and IgG3 antibodies with increasing age might reflect cumulative exposure to malaria parasites and possibly gradual maturation of the immune system over time as reported in other studies [26,27]. Both intermediate and highland strata had significantly lower mean IgG1 levels suggesting lower exposure to malaria as evidenced by the low malaria prevalence and splenomegaly [20]. 
The high levels of IgG1 and IgG3 in the lowland stratum, where malaria transmission is higher, suggests frequent exposure to malaria parasite as previously reported elsewhere $[28,29]$. The increase of IgG3 levels with age was slightly higher than that of IgG1 levels which might indicate that individuals with higher levels of IgG3 might be partially protected from malaria infection as reported in previous studies $[11,30]$.

Lowest malaria parasite prevalence in highlands in association with high total IgG levels, especially in those aged 10-19 years, might indicate recent history of malaria transmission in the highlands where malaria infection is usually low $[17,20,28]$ or could be due to the presence of cross-reactive antigens. The low total IgG levels in the intermediate stratum where bednet use was very high $(91.4 \%)$ is as reported elsewhere [31,32]. Previous studies using human sera from individuals in malaria endemic populations have found evidence of association between total IgG levels to MSP3 with a reduced subsequent risk of clinical malaria $[2,3]$.

The highest IgM levels in highland stratum in older individuals might suggest less exposure to malaria infection. It is known that non-protected individuals produce IgM antibodies mainly [2,14]. Furthermore, low IgM levels seen in the lowland stratum might be due to the continuous and intense malaria transmission. Notwithstanding this, individuals using bednets had significantly lower IgM levels.

\section{Conclusion}

Individuals with higher levels of IgG3 might be partially protected from malaria infection. Higher levels of total IgG and IgM in highlands might be due to low exposure to malaria infection, recent infection or presence of crossreactive antigens. Further studies of longitudinal nature are recommended. Data obtained from this study were used in selection of one village (Kwashemshi) for conducting MSP3 phase 1b malaria vaccine trial in Korogwe.

\section{List of abbreviations used}

ml: millilitre; RBCs: red blood cells; IgG0: total immunoglobulin G; IgG1: immunoglobulin G subclass 1; IgG3: immunoglobulin $\mathrm{G}$ subclass 3; IgM: immunoglobulin $\mathrm{M}$; EIR: entomological inoculation rate; ELISA: enzyme linked immunoSorbent assay; EDTA: ethylenediaminetetraacetic acid; rpm: revolutions per minute; $\mu \mathrm{L}$ : microlitre; ${ }^{\circ} \mathrm{C}$ : degrees Celsius; PBS: phosphate buffered saline; CA: Canada; UK: United Kingdom; DK: Denmark; $\mathrm{H}_{2} \mathrm{O}_{2}$ : hydrogen peroxide; TMB: tetramethlylbenzidine; $\mathrm{nm}$ : nanometer; $\mathrm{ng} / \mathrm{ml}$ : nanogram per millilitre; $\mu \mathrm{g} / \mathrm{ml}$ : microgram per millilitre; aa: amino acid; AIA: Afro Immuno Assay; AIC: akaike information criteria; n: number; mASL: metres above sea level; Hb: haemoglobin; g/dL: grammes per decilitre; AU: arbitrary unit;
WBCs: white blood cells; Hb: haemoglobin; temp: temperature; <: Less than; =: equal to; NC: negative controls; PC: positive controls.

\section{Acknowledgements}

This study was supported by a grant from African Malaria Network Trust (AMANET) and Ministry of Health and Social Welfare, Tanzania. We are greatly indebted to Professor Pierre Druilhe of Pasteur Institute for providing us with the antigen (MSP3). All individuals who agreed to participate in the study and the district and village leadership are thanked for their cooperation. We would like to acknowledge Drs. H.A. Msangeni and Samwel Sembuche for their assistance during the fieldwork by conducting clinical examination of the study participants. We thank Messieurs ASM Rutta, M.L. Kamugisha, D.R.T Minja and Dr. D. R. Ishengoma for their logistics assistance. All technologists, Messieurs J.A. Akida, E. Malecela, M.M. Chille, W. Chambo, J. Tupa, and Ms. J.Y. Sadi, M. Munisi, Z. Maumba are all thanked for their excellent technical support. Drivers, Messieurs Z. Kauzeni, T. Semdoe and S. Nguhu are all thanked for transporting the team to the field.

\section{Authors' contributions}

MDS assisted with proposal writing, study design, blood sample collection, laboratory analysis of blood samples, data interpretation and manuscript writing. BPM assisted with study design, data analysis, data interpretation and manuscript writing. MDS assisted with blood sample collection, laboratory analysis of samples and manuscript writing. JPL and MML assisted with proposal writing, study design, supervision of sample analysis, data interpretation and manuscript writing. All authors read and approved the final manuscript.

\section{Competing interests}

The authors declare that they have no competing interests.

\section{Received: 20 May 2009}

Accepted: 8 March 2010 Published: 8 March 2010

\section{References}

1. Breman JG: The ears of the hippopotamus: manifestations, determinants, and estimates of the malaria burden. Am J Trop Med Hyg 2001, 64:1-11.

2. Soe S, Theisen M, Roussilhon C, Aye KS, Druilhe P: Association between protection against clinical malaria and antibodies to merozoite surface antigens in an area of hyperendemicity in Myanmar: complementarity between responses to merozoite surface protein 3 and the 220kilodalton glutamate-rich protein. Infect Immun 2004, 72:247-252.

3. Riley EM, Allen SJ, Wheeler JG, Blackman MJ, Bennett S, Takacs B, et al: Naturally acquired cellular and humoral immune responses to the major merozoite surface antigen (PfMSP1) of Plasmodium falciparum are associated with reduced malaria morbidity. Parasite Immunol 1992, 14:321-337.

4. Druilhe $P$, Perignon JL: Mechanisms of defense against $P$. falciparum asexual blood stages in humans. Immunol Lett 1994, 41:115-120.

5. Perignon $J$, Druilhe P: Immune mechanisms underlying the premunition against Plasmodium falciparum malaria. Mem Inst Oswaldo Cruz 1994, 89(Suppl 2):51-53.

6. Alonso PL, Sacarlal J, Aponte JJ, Leach A, Macete E, Milman J, et al: Efficacy of the RTS, S/AS02A vaccine against Plasmodium falciparum infection and disease in young African children: randomised controlled trial. Lancet 2004, 364:1411-1420.

7. Ballou WR, Arevalo-Herrera M, Carucci D, Richie TL, Corradin G, Diggs C, et al: Update on the clinical development of candidate malaria vaccines. Am J Trop Med Hyg 2004, 71:239-247.

8. Bejon P, Peshu N, Gilbert SC, Lowe BS, Molyneux CS, Forsdyke J, et al: Safety profile of the viral vectors of attenuated fowlpox strain FP9 and modified vaccinia virus Ankara recombinant for either of 2 preerythrocytic malaria antigens, ME-TRAP or the circumsporozoite protein, in children and adults in Kenya. Clin Infect Dis 2006, 42:1102-1110.

9. Oeuvray C, Bouharoun-Tayoun H, Gras-Masse H, Bottius E, Kaidoh T, Aikawa $M$, et al: Merozoite surface protein-3: a malaria protein inducing antibodies that promote Plasmodium falciparum killing by cooperation with blood monocytes. Blood 1994, 84:1594-1602. 
10. Carvalho LJ, Oliveira SG, Theisen M, Alves FA, Andrade MC, Zanini GM, et al: Immunization of Saimiri sciureus monkeys with Plasmodium falciparum merozoite surface protein-3 and glutamate-rich protein suggests that protection is related to antibody levels. Scand J Immunol 2004, 59:363-372.

11. Sabchareon A, Burnouf $T$, Ouattara D, Attanath P, Bouharoun-Tayoun H, Chantavanich $\mathrm{P}$, et al: Parasitologic and clinical human response to immunoglobulin administration in falciparum malaria. Am J Trop Med Hyg 1991, 45:297-308.

12. Jafarshad A, Dziegiel MH, Lundquist R, Nielsen LK, Singh S, Druilhe PL: A novel antibody-dependent cellular cytotoxicity mechanism involved in defense against malaria requires costimulation of monocytes FcgammaRII and FcgammaRIII. J Immunol 2007, 178:3099-3106.

13. Bouharoun-Tayoun H, Oeuvray C, Lunel F, Druilhe P: Mechanisms underlying the monocyte-mediated antibody-dependent killing of Plasmodium falciparum asexual blood stages. J Exp Med 1995, 182:409-418.

14. Ndungu FM, Bull PC, Ross A, Lowe BS, Kabiru E, Marsh K: Naturally acquired immunoglobulin (Ig)G subclass antibodies to crude asexual Plasmodium falciparum lysates: evidence for association with protection for IgG1 and disease for IgG2. Parasite Immunol 2002, 24:77-82.

15. Sirima SB, Nebie I, Ouedraogo A, Tiono AB, Konate AT, Gansane A, et al: Safety and immunogenicity of the Plasmodium falciparum merozoite surface protein-3 long synthetic peptide (MSP3-LSP) malaria vaccine in healthy, semi-immune adult males in Burkina Faso, West Africa. Vaccine 2007, 25:2723-2732.

16. Lusingu JPA, Gesase $S$, Msham S, Francis F, Lemnge $M$, Seth $M$, Sembuche S, Rutta A, Minja D, Segeja MD, Bosomprah S, Cousens S, Noor R, Chilengi R, Druilhe P: Satisfactory safety and immunogenicity of MSP3 malaria vaccine candidate in Tanzanian children aged 12-24 months. Malaria J 2009, 8:163.

17. Bodker R, Akida J, Shayo D, Kisinza W, Msangeni HA, Pedersen EM, et al: Relationship between altitude and intensity of malaria transmission in the Usambara Mountains, Tanzania. J Med Entomol 2003, 40:706-717.

18. Maxwell CA, Chambo W, Mwaimu M, Magogo F, Carneiro IA, Curtis CF: Variation of malaria transmission and morbidity with altitude in Tanzania and with introduction of alphacypermethrin treated nets. Malar J 2003, 2:28.

19. Mmbando BP, Segeja MD, Msangeni HA, Sembuche SH, Ishengoma DS, Seth MD, Francis F, Rutta AS, Kamugisha ML, Lemnge MM: Epidemiology of malaria in an area prepared for clinical trials in Korogwe, northeastern Tanzania. Malaria J 2009, 8:165.

20. Lusingu JP, Vestergaard LS, Mmbando BP, Drakeley CJ, Jones C, Akida J, et al: Malaria morbidity and immunity among residents of villages with different Plasmodium falciparum transmission intensity in North-Eastern Tanzania. Malar J 2004, 3:26.

21. Mnzava AE, Kilama WL: Observations on the distribution of the Anopheles gambiae complex in Tanzania. Acta Trop 1986, 43:277-282.

22. Reyburn H, Mbatia R, Drakeley C, Bruce J, Carneiro I, Olomi R, Cox J, Nkya WM, Lemnge M, Greenwood BM, Riley EM: Association of transmission intensity and age with clinical manifestations and case fatality of severe Plasmodium falciparum malaria. JAMA 2005, 293(12):1461-1470

23. Nebie I, Tiono AB, Diallo DA, Samandoulougou S, Diarra A, Konate AT, Cuzin-Ouattara N, Thiesen M, Corradin G, Cousens S, Ouattara AS, IlboudoSanogo E, Sirima BS: Do antibody responses to malaria vaccine candidates influenced by the levels of malaria transmission protect from malaria?. Tropical Medicine and International Health 2008, 13(2):229-237.

24. Lusingu JPA, Gesase S, Msham S, Francis F, Lemnge M, Seth M, Sembuche S, Rutta A, Minja D, Segeja MD, Bosomprah S, Cousens S, Noor R, Chilengi R, Druilhe P: Satisfactory safety and immunogenicity of MSP3 malaria vaccine candidate in Tanzanian children aged 12-24 months. Malaria J 2009, 8:163.

25. Nebie I, Diarra A, Ouedraogo A, Soulama I, Bougouma EC, Tiono AB, et al: Humoral responses to Plasmodium falciparum blood-stage antigens and association with incidence of clinical malaria in children living in an area of seasonal malaria transmission in Burkina Faso, West Africa. Infect Immun 2008, 76:759-766.

26. Soe S, Khin SA, Htay A, Nay W, Tin A, Than S, et al: Premunition against Plasmodium falciparum in a malaria hyperendemic village in Myanmar. Trans R Soc Trop Med Hyg 2001, 95:81-84.
27. Dodoo D, Aikins A, Kusi KA, Lamptey H, Remarque E, Milligan P, et al: Cohort study of the association of antibody levels to AMA1, MSP119, MSP3 and GLURP with protection from clinical malaria in Ghanaian children. Malar J 2008, 7:142.

28. Drakeley CJ, Corran PH, Coleman PG, et al: Estimating medium and long term trends in malaria transmission by using serological markers of malaria exposure. Proceedings of the National Academy of Sciences USA 102:5108-5113.

29. Tongren JE, Drakeley CJ, McDonald SL, Reyburn HG, Manjurano A Nkya WM, Lemnge MM, Gowda CD, Todd JE, Corran PH, Riley EM: Target antigen, age and duration of antigen exposure independently regulate Immunoglobulin G subclass switching in malaria. Infection Immun 2006, 74:257-264.

30. Pleass RJ, Woof JM: Fc receptors and immunity to parasites. Trends Parasitol 2001, 17:545-551.

31. Askjaer N, Maxwell C, Chambo W, et al: Insecticide treated bednets reduce plasma antibody levels and limit the repertoire of antibodies to Plasmodium falciparum variant surface antigens. Clinical and disgnostic Laboratory Immunology 2001, 8:1289-1291.

32. Nebie I, Cuzin-Ouattara N, Diallo DA, et al: Humoral responses to defined malaria antigens in children living since birth under insecticide treated curtains in Burkina Faso. Acta Tropics 2003, 88:17-25.

\section{Pre-publication history}

The pre-publication history for this paper can be accessed here:http://www. biomedcentral.com/1471-2334/10/55/prepub

doi:10.1186/1471-2334-10-55

Cite this article as: Segeja et al:: Acquisition of antibodies to merozoite surface protein 3 among residents of Korogwe, north eastern Tanzania. BMC Infectious Diseases 2010 10:55.

\section{Submit your next manuscript to BioMed Central and take full advantage of:}

- Convenient online submission

- Thorough peer review

- No space constraints or color figure charges

- Immediate publication on acceptance

- Inclusion in PubMed, CAS, Scopus and Google Scholar

- Research which is freely available for redistribution

Submit your manuscript at www.biomedcentral.com/submit
C Biomed Central 